\title{
Review and update of benign prostatic hyperplasia in general practice
}

\author{
Manasi Jiwrajka, William Yaxley, \\ Marlon Perera, Matt Roberts, \\ Nigel Dunglison, John Yaxley, \\ Rachel Esler
}

\section{Background \\ Benign prostatic hyperplasia $(\mathrm{BPH})$ is the most common benign tumour in men. Although men with BPH often need medical or surgical management from a urologist at some point throughout the timeline of their disease, most men are initially assessed and managed by a general practitioner (GP) in the primary healthcare setting.}

\section{Objectives}

The aim of this article is to highlight the principles of the pathogenesis, presentation, assessment and management of $\mathrm{BPH}$ in a primary care setting

\section{Discussion}

Between 2009 and 2011, BPH was managed by GPs at approximately 228,000 general practice visits per annum in Australia. Several changes in pharmaceutical agents and surgical intervention have occurred over the past decade. As a result, it is imperative that GPs remain up to date with assessment and management of $\mathrm{BPH}$, are aware of new therapies and understand when to refer to a urologist.
IT IS COMMON FOR MEN to present to a general practitioner (GP) with symptoms suggestive of bladder outflow obstruction, which is often due to benign prostatic enlargement (BPE). Benign prostatic hyperplasia $(\mathrm{BPH})$ is the histological cause of BPE, which often results in lower urinary tract symptoms (LUTS) related to voiding, storage or post-micturition. ${ }^{1}$ Not all LUTS in men are due to BPE, and other causes of voiding dysfunction require exclusion (Table 1 ). ${ }^{2}$ Management of LUTS due to BPE depends on symptom severity or complicating factors and includes observation (for men with minimal symptoms), medical therapy, minimally invasive surgical procedures, endoscopic prostatectomy and, occasionally, abdominopelvic surgery for very large prostates.

\section{Important history and examination features}

International guidelines highlight the importance of determining the severity of LUTS and identifying complicating factors such as urinary retention, macroscopic haematuria, urinary tract infection (UTI) or a personal or family history of prostate cancer. Men may describe (i) voiding (bladder emptying) symptoms such as weak stream, hesitancy and intermittency of flow or (ii) storage (bladder filling) symptoms such as urgency, daytime frequency and nocturia. A predominance of storage symptoms would require exclusion of other conditions such as primary bladder pathology/malignancy, diabetes mellitus, ischaemic heart disease and medications with diuretic properties. ${ }^{3}$ In cases where the primary complaint is nocturia, efforts should first be made to exclude nocturnal polyuria (then associated factors such as obstructive sleep apnoea) as the cause of symptoms. The use of a frequency-volume chart or voiding diary, and International Prostate Symptom Score (IPSS) tools, help to assess symptom severity and bother affecting quality of life (QoL; Table 2). ${ }^{4}$

The aim of physical examination is to exclude a palpable bladder as well as phimosis, meatal stenosis or other pathology, including balanitis. A digital rectal examination (DRE) is recommended to evaluate the size of the prostate and exclude a grossly malignant or hard prostate nodule suggestive of prostate cancer, tenderness suggestive of prostatitis, and constipation. ${ }^{5}$

\section{Initial investigations}

Initial investigations aim to exclude sinister causes of LUTS or complications of bladder outflow obstruction that require immediate treatment. Such investigations (Table 3) include urinalysis (to exclude haematuria, proteinuria and pyuria), serum creatinine and estimated glomerular filtration rate (eGFR). ${ }^{6}$ Urine cytology should be considered in the presence of haematuria, risk factors for urothelial carcinoma, or significant storage symptoms. In patients with moderate-to-severe symptoms or an abnormal serum creatinine, a renal tract ultrasound will show bladder capacity and post-void urine residual volume, allow for assessment for hydronephrosis and provide an estimation of prostate volume. ${ }^{5}$ Computerised tomography is not routinely recommended unless complicating features are suspected. ${ }^{5,6}$

Some men are concerned that their urinary symptoms may be due to an underlying prostate cancer. Prostatespecific antigen (PSA) testing remains controversial both in Australia and 
internationally. The Royal Australian College of General Practitioners (RACGP) recommends against PSA screening, but acknowledges that the PSA debate remains unclear and open to individual interpretation. ${ }^{7}$ The Prostate Cancer Foundation of Australia and Cancer Council Australia guidelines from 2016 recommend PSA testing every two years for men aged 50-69 years at average risk of prostate cancer. ${ }^{8}$ This recommendation is supported by the Urological Society of Australia and New Zealand (USANZ).

\section{Management}

Treatment is mostly determined by bother of symptoms, effect on QoL or whether any complicating features are identified. A conservative approach, with reassurance and behavioural modification, can be considered in men with mild, non-bothersome LUTS and normal baseline investigations, as their risk of progression is low. ${ }^{9,10}$ Behavioural modifications include reducing diuretics (caffeine, alcohol), bladder irritants (acidic, spicy foods), evening fluid intake and constipation. ${ }^{9,10}$ Bladder training and pelvic floor exercises may improve bladder capacity and reduce storage symptoms. A yearly GP review of symptoms, with urinalysis and creatinine/eGFR, is suggested to monitor for progression. ${ }^{2}$

\section{Medical therapy}

Men with bothersome symptoms in the absence of complicating factors are appropriate candidates for a trial of medical therapy. ${ }^{6}$ Monotherapy is usually initiated with an alpha-adrenoceptor antagonist. Combined therapy with a 5-alpha reductase inhibitor (5-ARI) may further improve symptoms in men with large prostate volumes.

\section{Alpha-adrenoceptor antagonists}

Alpha-1 adrenoceptor blockade results in smooth muscle relaxation in the prostate and bladder neck. ${ }^{3}$ Uroselective agents, such as alfuzosin, silodosin, tamsulosin and terazosin, have been shown to produce comparable improvement in symptom score and maximal urinary flow rate with fewer systemic side effects. ${ }^{3,11}$ Prazosin is cheaper than other agents and is commonly used but has a less favourable side-effect profile and requires multiple daily dosing; thus, it is not recommended by international $\mathrm{BPH}$ guidelines. ${ }^{3}$

Men should be warned of the side effects of alpha-adrenoceptor antagonists, including retrograde ejaculation (higher with uroselective agents), erectile dysfunction, nasal congestion, hypotension, dizziness and tachycardia. ${ }^{1}$ Caution is also required

Table 1. Differential diagnoses for lower urinary tract symptoms

\begin{tabular}{|c|c|c|}
\hline $\begin{array}{l}\text { Benign and neoplastic } \\
\text { conditions of the lower } \\
\text { urinary tract }\end{array}$ & $\begin{array}{l}\text { Neurological } \\
\text { conditions }\end{array}$ & $\begin{array}{l}\text { Other causes of lower } \\
\text { urinary tract symptoms }\end{array}$ \\
\hline $\begin{array}{l}\text { - Urinary tract infection } \\
\text { - Prostatitis } \\
\text { - Bladder calculi } \\
\text { - Interstitial cystitis } \\
\text { - Urethral stricture } \\
\text { - Phimosis } \\
\text { - Overactive bladder } \\
\text { - syndrome } \\
\text { - Prostate cancer } \\
\text { - Urothelial carcinoma of } \\
\text { the bladder including } \\
\text { carcinoma in situ } \\
\text { - Urethral cancer }\end{array}$ & $\begin{array}{l}\text { - Parkinson's disease } \\
\text { - Stroke/cerebrovascular } \\
\text { accident } \\
\text { - Multiple sclerosis } \\
\text { - Cerebral atrophy } \\
\text { - Head injury } \\
\text { - Spinal cord injury/ } \\
\text { surgery or degenerative } \\
\text { disc disease } \\
\text { - Prior pelvic surgery }\end{array}$ & $\begin{array}{l}\text { - Polyuria from renal or } \\
\text { cardiac dysfunction } \\
\text { - Nocturnal polyuria and } \\
\text { sleep apnoea } \\
\text { - latrogenic from } \\
\text { medications }\end{array}$ \\
\hline
\end{tabular}

in men considering cataract surgery, given the increased risk of floppy iris syndrome. ${ }^{3,12}$

\section{5-alpha reductase inhibitors}

5-ARIs inhibit the conversion of testosterone to dihydrotestosterone (DHT) to reduce prostate growth and prostate volume. ${ }^{13}$ The most common 5-ARIs prescribed on the Australian Pharmaceutical Benefits Scheme (PBS) are dutasteride and finasteride. Dutasteride inhibits type 1 and type 2 isoenzymes of 5 -alpha reductase, as opposed to type 2 inhibition alone with finasteride. ${ }^{14} 5$-ARIs are most effective when prostate volume is $>40 \mathrm{~mL}^{5}$

The most common side effects of 5-ARIs are erectile dysfunction, decreased libido, decreased ejaculate and decreased sperm count. ${ }^{15}$ In contrast to the rapid onset of action of alpha-adrenoceptor antagonists, 5-ARIs can take several months before maximum improvement in symptoms is obtained. ${ }^{1}$ Men should be warned that 5-ARI therapy can decrease PSA levels by approximately $50 \%$ after 6-12 months of treatment. ${ }^{16,17}$ As a result, in men on a 5-ARI, an increase in PSA above the nadir should prompt closer evaluation of PSA levels to exclude an upward trend suggestive of prostate cancer, rather than waiting for the PSA to be elevated outside the reference range before considering urological evaluation.

\section{Combination therapy}

Since 2016, tamsulosin plus dutasteride has been available to GPs to prescribe as a combined formulation without specialist approval. ${ }^{18}$ This fixed-dose combination is subsidised by the PBS and therefore available at a lower cost than both agents separately. $^{2}$

Two randomised controlled trials of more than 3000 men compared combination therapy with monotherapy. Overall, combination therapy was superior to either alpha-adrenoceptor antagonist or 5-ARI therapy alone in improving LUTS and reducing progression. ${ }^{12}$ For men with a prostate volume of $>40 \mathrm{~mL}$ and a PSA of $>1.5$, 
Table 2. The International Prostate Symptom Score ${ }^{4}$

\begin{tabular}{|c|c|c|c|c|c|c|}
\hline $\begin{array}{l}\text { Urinary symptoms over the past month } \\
\text { (symptom score criteria) }\end{array}$ & Not at all & $\begin{array}{l}\text { Less than one } \\
\text { time in five }\end{array}$ & $\begin{array}{l}\text { Less than } \\
\text { half the time }\end{array}$ & $\begin{array}{l}\text { About half } \\
\text { the time }\end{array}$ & $\begin{array}{l}\text { More than } \\
\text { half the time }\end{array}$ & $\begin{array}{l}\text { Almost } \\
\text { always }\end{array}$ \\
\hline
\end{tabular}

\section{Incomplete emptying}

How often have you had a sensation of not emptying your bladder completely after you

0

2

3

4

5

finished urinating?

\section{Frequency}

How often have you had to urinate less

0

123

than two hours after you finished urinating?

\section{Intermittency}

How often have you found you stopped and started again several times when you 0

1

2

2

5 urinated?

\section{Urgency}

How often have you found it difficult to

0

12

$2 \quad 3$

4

$4 \quad 5$

postpone urination?

\section{Weak stream}

How often have you had a weak urinary

0

1

12

2

4

45

stream?

\section{Straining}

How often have you had to push or strain

to begin urination?

$\begin{array}{lllll}0 & 2 & 3 & 4\end{array}$

None One time $\quad$ Twotimes Three times Fourtimes $\begin{gathered}\text { Five or mor } \\ \text { times }\end{gathered}$

\section{Nocturia}

How many times did you most typically get up to urinate from the time you went to bed at night until the time you got up in the morning?

Quality of life due to urinary problems

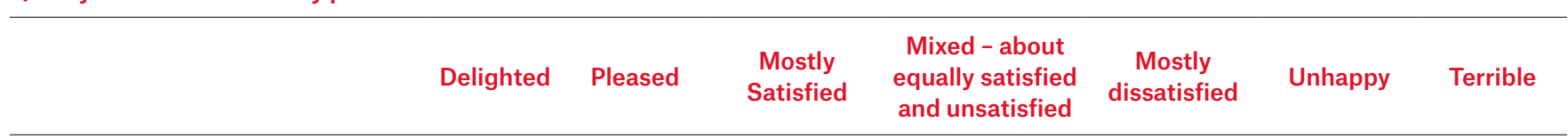

If you were to spend the rest of your life with your urinary condition just the way it is now,

how would you feel about that?

\section{The final score is the sum of questions 1-7}

combination therapy resulted in greater reductions in the risk of urinary retention or the need for surgery than monotherapy. ${ }^{19}$ However, urological opinion varies regarding balancing the benefit of combination therapy over monotherapy against the risk of increased sexual dysfunction. ${ }^{12,20}$

\section{Phosphodiesterase 5 inhibitors}

BPE and erectile dysfunction can occur concomitantly, and phosphodiesterase 5 (PDE5) inhibitors (eg sildenafil) have been associated with some improvement in voiding symptoms. ${ }^{3}$ Though not traditionally recognised as a first-line treatment option, several randomised controlled trials have shown that PDE5 inhibitors improve IPSS, symptoms and QoL, compared with placebo. ${ }^{3}$ Furthermore, the combination of an alpha-adrenoceptor antagonist and PDE5 inhibitor is superior to PDE5 inhibitor monotherapy. $^{21}$ 
Table 3. Initial investigations in the general practice setting

\begin{tabular}{lll}
\hline Investigation & Reason for investigation & Comments \\
\hline Urinalysis & $\begin{array}{l}\text { Exclude leucocytosis, haematuria, proteinuria, } \\
\text { pyuria and glycosuria }\end{array}$ & Follow up with urine culture if abnormality on urinalysis \\
\hline $\begin{array}{l}\text { Serum creatinine/ } \\
\text { estimated glomerular } \\
\text { filtration rate (eGFR) }\end{array}$ & $\begin{array}{l}\text { Exclude renal injury from primary renal } \\
\text { dysfunction or high-pressure bladder outflow } \\
\text { obstruction }\end{array}$ & $\begin{array}{l}\text { Follow up with imaging if abnormal eGFR. Can be useful } \\
\text { as a follow-up test if renal impairment is suspected }\end{array}$ \\
\hline $\begin{array}{l}\text { Urinary tract ultrasound } \\
\text { Assessment of prostate volume, bladder } \\
\text { hall and residual urine; used to exclude }\end{array}$ & $\begin{array}{l}\text { Bladder scanners are available for general practitioner } \\
\text { use to calculate residual volume, but a formal ultrasound } \\
\text { requires a radiology unit }\end{array}$ \\
\hline $\begin{array}{l}\text { Prostate-specific } \\
\text { antigen (PSA) }\end{array}$ & Exclude prostate cancer & $\begin{array}{l}\text { Controversial; most guidelines recommend the use of } \\
\text { serum PSA if prostate cancer diagnosis will influence } \\
\text { management or if the test will assist in decision making }\end{array}$ \\
\hline
\end{tabular}

\section{Triggers for urological referral}

There are numerous clinical indications for urological referral including urinary retention, evidence of hydronephrosis on ultrasound, symptoms refractory to medical management, recurrent UTIs, gross haematuria, bladder stones, renal insufficiency or large bladder diverticula. ${ }^{1,2}$

\section{Surgical management}

\section{Endoscopic prostatectomy}

Transurethral resection of the prostate (TURP) is the gold standard surgical treatment for symptomatic BPH. Risks are well established and include retrograde ejaculation, impotence, incontinence, urethral stricture, bladder neck contracture, bleeding or perforation of prostate capsule resulting in 'TURP syndrome'. ${ }^{1}$ Laser vaporisation and enucleation treatments are also used because of shorter hospitalisation duration, shorter catheter time, lower transfusion rates and less clot retention, compared with a TURP; however, no difference in symptom improvement or QoL has been shown. ${ }^{22-24}$

\section{Minimally invasive surgical therapy}

Transurethral incision of the prostate involves an incision of the bladder neck without removal of prostatic tissue. It is used for men with small prostates and has outcomes comparable with TURP. ${ }^{1}$ More recently, aquablation has served to reduce the morbidity of traditional approaches, especially retrograde ejaculation and bleeding; however, longitudinal outcome data are limited. ${ }^{25}$ The prostatic urethral lift procedure, which deploys adjustable implants to retract obstructing lateral prostatic lobes, was approved by the Therapeutic Goods Administration in August 2012 and has become a commonly performed day procedure..$^{26,27}$ Patients are often catheter-free on discharge, and there have been no reported de novo cases of sexual dysfunction. ${ }^{28}$ The prostatic urethral lift is usually unsuitable for men with urinary retention, obstructing median lobes or prostates $>80 \mathrm{~mL}^{29}$

\section{Conclusions}

LUTS are a common reason for men to present for GP review. Uncomplicated LUTS and minimal bother warrant an initial conservative approach. Men with more bothersome symptoms can be initially managed with an alphaadrenoceptor antagonist, while an additional 5-ARI can be considered for men with larger prostates. Surgery is recommended for men who are bothered by symptoms and fail to respond to medical management or have complications such as hydronephrosis, recurrent UTIs, progressive deterioration of residual volume, macroscopic haematuria or very poor maximum velocity on uroflow studies.

\section{Authors}

Manasi Jiwrajka BA, MBBS, MPhil candidate, Resident Medical Officer, Urology Department, Royal Brisbane and Women's Hospital, Brisbane, Qld; Faculty of Medicine, The University of Queensland, Brisbane, Qld; Queensland Institute of Medical Research, Brisbane, Qld. mjiwrajka@gmail.com William Yaxley MBBS, Resident Medical Officer, Associate Lecturer, Urology Department, Royal Brisbane and Women's Hospital, Brisbane, Qld; Faculty of Medicine, The University of Queensland, Brisbane, Qld

Marlon Perera MBBS, Urology Registrar, PhD candidate, Urology Department, Royal Brisbane and Women's Hospital, Brisbane, Qld; Faculty of Medicine, The University of Queensland, Brisbane, Qld; Department of Surgery, Austin Health, University of Melbourne, Vic

Matt Roberts MBBS, PhD, Urology Registrar and Lecturer, Urology Department, Royal Brisbane and Women's Hospital, Brisbane, Qld; Faculty of Medicine, The University of Queensland, Brisbane, Qld Nigel Dunglison MBBS, Consultant Urologist, Urology Department, Royal Brisbane and Women's Hospital, Brisbane, Qld

John Yaxley MBBS, Consultant Urologist, Associate Professor, Urology Department, Royal Brisbane and Women's Hospital, Brisbane, Qld; Faculty of Medicine, The University of Queensland, Brisbane, QId

Rachel Esler MBBS, Consultant Urologist, Director of Unit, Urology Department, Royal Brisbane and

Women's Hospital, Brisbane, QId

Competing interests: None.

Provenance and peer review: Not commissioned, externally peer reviewed.

\section{References}

1. McAninch JW, Lue TF. Smith and Tanagho's general urology. New York: McGraw-Hill, 2013.

2. Woo HH, Gillman MP, Gardiner R, Marshall V, Lynch WJ. A practical approach to the management of lower urinary tract symptoms among men. Med J Aust 2011;195(1):34-39.

3. Lawrentschuk N, Perera M. Endotext: Benign prostate disorders. South Dartmouth, USA: MDText.com Inc, updated 14 March 2016.

4. McConnell JD, Barry MJ, Bruskewitz RC. Benign prostatic hyperplasia: Diagnosis and treatment. Agency for Health Care Policy and Research. Clin Pract Guidel Quick Ref Guide Clin 1994;(8):1-17. 
5. European Association of Urology. Guidelines on the management of non-neurogenic male lower urinary tract symptoms (LUTS), incl. benign prostatic obstruction (BPO). The Netherlands: EAU, 2015.

6. Nickel JC, Méndez-Probst CE, Whelan TF, Paterson RF, Razvi H. 2010 update: Guidelines for the management of benign prostatic hyperplasia. Can Urol Assoc J 2010;4(5):310-16.

7. Trevana L, Glasziou P, Rowe L, Ackermann E. Patient information sheet: Should I have prostate cancer screening? East Melbourne, Vic: RACGP, August 2015. Available at www.racgp.org.au/yourpractice/guidelines/prostate-cancer [Accessed 3 July 2017].

8. PSA Testing Guidelines Expert Advisory Panel. PSA testing and early management of test-detected prostate cancer: Clinical practice guidelines. Sydney: Prostate Cancer Foundation of Australia and Cancer Council Australia, 2016. Available at www.prostate.org.au/media/612113/PSA-TestingGuidelines.pdf [Accessed 3 July 2017].

9. Brown CT, Yap T, Cromwell DA, et al. Self management for men with lower urinary tract symptoms: Randomised controlled trial. BMJ 2007;334(7583):25.

10. Yap TL, Brown C, Cromwell DA, van der Meulen J, Emberton M. The impact of selfmanagement of lower urinary tract symptoms on frequency-volume chart measures. BJU Int 2009:104(8):1104-08. doi: 10.1111/j.1464410X.2009.08497.x.

11. Chapple ChR, Montorsi F, Tammela TL, Wirth M, Koldewijn E, Fernandez Fernandez E. [Silodosin therapy for lower urinary tract symptoms in men with suspected benign prostatic hyperplasia: Results of an international, randomized, doubleblind, placebo- and active-controlled clinical trial performed in Europe]. Urologiia 2012;(5):38-42, 44-45.

12. American Urological Association. Guideline: Management of Benign Prostatic Hyperplasia (BPH). Linthicum, MD: American Urology Association, 2010. Available at www.auanet.org/guidelines/ benign-prostatic-hyperplasia-(2010-reviewed-andvalidity-confirmed-2014)\#x25122010 [Accessed 1 July 2017].

13. Roehrborn CG. 5-alpha-reductase inhibitors prevent the progression of benign prostatic hyperplasia. Rev Urol 2003;5 Suppl 5:S12-21.

14. Hudak SJ, Hernandez J, Thompson IM. Role of 5 alpha-reductase inhibitors in the management of prostate cancer. Clin Interv Aging 2006;1(4):425-31.
15. Naslund MJ, Miner M. A review of the clinical efficacy and safety of 5alpha-reductase inhibitors for the enlarged prostate. Clin Ther 2007;29(1):17-25.

16. Marihart S, Harik M, Djavan B. Dutasteride: A review of current data on a novel duel inhibitor of 5alpha reductase. Rev Urol 2005:7(4):203-10.

17. Choi YH, Cho SY, Cho IR. The different reduction rate of prostate-specific antigen in dutasteride and finasteride. Korean J Urol 2010;51(10):704-08. doi: 10.4111/kju.2010.51.10.704.

18. Willcock S, Patel M; Palin Communications. Easier access to medicines for men with enlarged prostates following medicine reimbursement changes. Boronia, Vic: GSK Australia, 2016. Available at https://au.gsk.com/en-au/media/ press-releases/2016/easier-access-to-medicinesfor-men-with-enlarged-prostates-followingmedicine-reimbursement-changes [Accessed 3 July 2017]

19. Roehrborn CG, Barkin J, Siami P, et al. Clinical outcomes after combined therapy with dutasteride plus tamsulosin or either monotherapy in men with benign prostatic hyperplasia (BPH) by baseline characteristics: 4-year results from the randomized, double-blind Combination of Avodart and Tamsulosin (CombAT) trial. BJU Int 2011;107(6):946-54. doi: 10.1111/j.1464410X.2011.10124.X

20. Roehrborn CG, Oyarzabal Perez I, Roos EPM, et al. Efficacy and safety of a fixed-dose combination of dutasteride and tamsulosin treatment (Duodart ${ }^{\circledR}$ ) compared with watchful waiting with initiation of tamsulosin therapy if symptoms do not improve, both provided with lifestyle advice, in the management of treatment-naïve men with moderately symptomatic benign prostatic hyperplasia: 2-year CONDUCT study results. BJU Int 2015;116(3):450-59. doi: 10.1111/bju.13033.

21. Kim SW, Park NC, Lee SW, et al. Efficacy and safety of a fixed-dose combination therapy of tamsulosin and tadalafil for patients with lower urinary tract symptoms and erectile dysfunction: Results of a randomized, double-blinded, activecontrolled trial. J Sex Med 2017;14(8):1018-27. doi: 10.1016/j.jsxm.2017.06.006.

22. Wang K, Li Y, Teng JF, Zhou HY, Xu DF, Fan Y. Transurethral plasmakinetic resection of the prostate is a reliable minimally invasive technique for benign prostate hyperplasia: A meta-analysis of randomized controlled trials. Asian J Androl 2015;17(1):135-42. doi: 10.4103/1008-682X.138191.

23. Ow D, Papa N, Perera M, et al. Trends in the surgical treatment of benign prostatic hyperplasia in a tertiary hospital. ANZ J Surg 2018;88(1-2):9599. doi: 10.1111/ans.13904.
24. Jhanwar A, Sinka RJ, Bansal A, Prakash G, Singh $\mathrm{K}$, Singh V. Outcomes of transurethral resection and holimiun laser enucleation in more than 60 $\mathrm{g}$ of prostate: A prospective randomized study. Urol Ann 2017;9(1):45-50. doi: 10.4103/09747796.198904.

25. Christidis D, McGrath S, Perera M, Manning T, Bolton D, Lawrentschuk N. Minimally invasive surgical therapies for benign prostatic hypertrophy: The rise in minimally invasive surgical therapies. Prostate Int 2017;5(2):41-46. doi: 10.1016/j.prnil.2017.01.007.

26. NeoTract Inc. UroLift - FAQs. Artarmon, NSW: NeoTract Inc, 2015-17. Available at http://urolift. com.au/doctors/faqs [Accessed 10 June 2017].

27. Perera M, Roberts MJ, Doi SA, Bolton D. Prostatic urethral lift improves urinary symptoms and flow while preserving sexual function for men with benign prostatic hyperplasia: A systematic review and meta-analysis. Eur Urol 2015;67(4):704-13. doi: 10.1016/j.eururo.2014.10.031.

28. Roehrborn CG, Barkin J, Gange SN, et al. Five year results of the prospective randomized controlled prostatic urethral L.I.F.T. study. Can J Urol 2017;24(3):8802-13.

29. Pushkaran A, Stainer V, Muir G, Shergill IS. Urolift - Minimally invasive surgical BPH management. Expert Rev Med Devices 2017;14(3):223-28. doi: 10.1080/17434440.2017.1296762.

correspondence ajgp@racgp.org.au 